\title{
Avaliação protéica de uma nova multimistura com base no milho QPM BR 473
}

\section{Protein evaluation of a nutritional supplement based on QPM BR 473 maize}

\author{
Enara Cristina Silva GLÓRIA 1 \\ Nízia Araújo Vieira ALMEIDA² \\ Alexandre Sylvio Vieira da $\operatorname{COSTA}^{3}$ \\ Edinete HENRIQUES JÚNIOR ${ }^{4}$ \\ Sandra Lagatta MARTINS ${ }^{4}$ \\ Heberth de PAULA ${ }^{5}$ \\ Marcelo Eustáquio SILVA ${ }^{5}$ \\ Rinaldo Cardoso dos SANTOS 5 \\ Luiz Cosme Cotta MALAQUIAS 3
}

\section{RE S U M O}

A multimistura tem sido utilizada no Brasil pela Pastoral da Criança, em parceria com governos municipais, a fim de reduzir a desnutrição infantil. Não obstante, a eficácia deste suplemento tem sido constantemente arguida, devido à possível presença de fatores antinutricionais. No presente trabalho descrevemos a avaliação biológica de um suplemento contendo milho QPM BR473. Trinta e seis ratos Wistar machos, com 21-23 dias de idade, foram divididos em seis grupos de seis animais cada e alimentados com dietas de caseína contendo multimistura pura, com QPM BR473, láctea (contendo leite em pó), láctea contendo QPM BR473 ou a multimistura proposta (contendo QPM BR473, farinhas de aveia, soja e banana e açúcar mascavo). Mediu-se a Retenção Protéica Líquida. A condição microbiológica dos suplementos e seu custo foram também determinados. Os resultados obtidos mostraram que O QPM BR473 pode ser usado em suplementos nutricionais, com alto valor nutritivo, expresso por sua qualidade protéica, e com baixa relação custo/benefício.

Termos de indexação: milho, qualidade proteica, multimistura.

\footnotetext{
1 Secretaria Municipal da Educação de Governador Valadares. Governador Valadares, MG, Brasil.

2 Secretaria Municipal da Saúde de Governador Valadares. Governador Valadares, MG, Brasil.

${ }^{3}$ Laboratório de Pesquisa em Imunologia, Faculdade de Ciências, Educação e Letras, Universidade Vale do Rio Doce. R. Israel Pinheiro, 2000, Bairro Universitário, 35020-220, Governador Valadares, MG, Brasil.

${ }^{4}$ Empresa de Assistência Técnica e Extensão Rural do Estado de Minas Gerais. Secretaria de Estado de Agricultura. Belo Horizonte, MG, Brasil.

${ }^{5}$ Escola de Nutrição, Departamento de Alimentos, Universidade Federal de Ouro Preto. R. Diogo de Vasconcelos, 122, 35400000, Ouro Preto, MG. Correspondência para/Correspondence to: M.E. SILVA.
} 


\section{A B S T R A C T}

Nutritional supplements, known as "multimisturas", prepared with low cost ingredients have been distributed in Brazil by municipal governments, in partnership with non-governmental organizations, in order to reduce infant malnutrition. Nevertheless the efficacy of these supplements has been constantly argued, due to the possible presence of anti-nutritional factors. The present work describes the biological evaluation of a supplement containing Quality Protein Maize BR 473. Thirty six 21-23-day old male Wistar rats were divided into six groups of six animals each. The groups were fed casein diets, each containing respectively: "multimistura", "multimistura" with QPM BR 473, "multimistura" with powdered milk, "multimistura" with powderedmilk and QPM BR 473 or the proposed new supplement (containing QPM BR 473 flour, oat meal, soybean flour, brown sugar and banana meal). Net protein retention was measured. Microbiological condition and cost of the supplements were also determined. The results showed that QPM BR 473 can be used in nutritional supplements, with high nutritional value, as expressed by its protein quality, and low cost/benefit ratio.

Index terms: maize, protein quality, nutritional supplement.

\section{N T R O D U Ç Ã O}

No combate à desnutrição, instituições não governamentais e alguns governos municipais vêm estabelecendo parcerias para a utilização de multimisturas. Trata-se de um tipo de alimentação alternativa, constituída basicamente por farelo de trigo ou arroz, pós da casca de ovo e da folha de mandioca, farinha de trigo e fubá comum ${ }^{1-4}$. Tal prática tem sido alvo de polêmica, visto não haver comprovação científica de eficácia dessa multimistura como suplemento nutricional para crianças desnutridas 5 .

Em decorrência da expansão do uso dessa multimistura como medida de combate à desnutrição infantil, várias instituições de ensino e pesquisa passaram a desenvolver estudos que pudessem respaldar cientificamente seu uso. As pesquisas direcionadas à multimistura e seus componentes isoladamente, têm como principal objetivo determinar o valor nutritivo, a presença de fatores antinutricionais e/ou tóxicos e o padrão microbiológico. Entre essas, destacam-se o informe técnico "Programas Emergenciais de Alimentos" 6 e uma revisão apresentada por Bittencourt? ${ }^{7}$. Ambos apontam a impropriedade do uso da multimistura em dietas destinadas a seres humanos, considerando que o valor nutritivo de qualquer alimento não pode ser estabelecido unicamente com base na quantidade de seus nutrientes, pois sua qualidade nutricional provavelmente é determinada por outros fatores.

Ensaios biológicos, utilizando ratos como modelo experimental, têm sido realizados sob diferentes condições; os resultados obtidos não indicam ser a multimistura um suplemento adequado, quer na recuperação, quer na manutenção do estado nutricional dos animais ${ }^{8,9}$. O acompanhamento nutricional de crianças também tem sido realizado, com o intuito de avaliar o impacto das multimisturas na evolução ponderal e na alteração de parâmetros biológicos ${ }^{10}$.

A precariedade de respaldo científico que justifique o consumo da multimistura tradicional tem gerado procedimento em novas fórmulas, mais seguras e avaliadas cientificamente. Dentro desse contexto, propomos o uso do fubá QPM BR 473 como principal componente de uma nova formulação.

O milho QPM BR 473, variedade desenvolvida pela Embrapa/CNPMS de Sete Lagoas, é um alimento de alta qualidade protéica pelo seu perfil aminoacídico. O milho QPM BR 473 apresenta teores de aminoácidos essenciais (lisina e triptofano) significativamente superiores aos do 
milho comum e valor protéico correspondente a $83,5 \%$ das proteínas do leite. Tais dados significam que o milho QPM brasileiro constitui uma fonte protéica de alto valor biológico ${ }^{11}$. Na Guatemala, na Colômbia, no Peru, em Gana e nos Estados Unidos, o uso do milho QPM mostrou resultados surpreendentes na recuperação de crianças desnutridas ${ }^{12}$. Em Gana, um programa nacional de nutrição instituiu a utilização do mingau e da papa, produzidos com o fubá do milho QPM, como alimento para a recuperação nutricional de bebes e pré-escolares acometidos pela desnutrição protéico-energético (marasmo) e pela desnutrição protéica (kwashiorkor) ${ }^{12}$. Essas preparações, oferecidas como os únicos constituintes da dieta, têm sido responsáveis pela sobrevivência de milhares de crianças naquele país ${ }^{12}$

O presente trabalho teve como objetivo a avaliação biológica de uma nova formulação, cuja base é o milho QPM BR 473. Avaliou-se também uma preparação contendo leite em pó integral, a qual foi denominada de "multimistura láctea". A realização deste ensaio é parte integrante do "Projeto de Produção e Consumo do milho QPM BR473 como um dos fatores na recuperação de crianças desnutridas no Município de Governador Valadares, MG", que conta com a participação da EMATER-MG, Pastoral da Criança, Secretaria Municipal de Educação de Minas Gerais, Secretaria Municipal de Saúde e Universidade Vale do Rio Doce.

\section{MATERIALE MÉTODOS}

Foram utilizados ratos da linhagem Wistar, com idade entre 21-23 dias, machos, albinos, recém-desmamados. Trinta e seis ratos foram separados em grupos de seis animais por dieta testada e colocados em gaiolas individuais. Estas foram devidamente identificadas com o tipo de dieta e o número específico do animal e equipados com comedouro e bebedouro individualizados. Todos os animais receberam água e dietas ad libitum.
A composição das diferentes multimisturas avaliadas é apresentada na Tabela 1. As dietas foram preparadas de forma a compensar as pequenas diferenças de energia e proteínas entre as diferentes multimisturas, tornando-se assim isoprotéicas e isoenergéticas. Além disso, sua preparação seguiu a recomendação da Association of Official Agricultural Chemists (AOAC) dos Estados Unidos da América para a avaliação biológica da qualidade protéica ${ }^{13}$. À multimistura láctea foi adicionado leite em pó integral, marca Itambé ${ }^{\circledR}$, adquirido no comércio local. Preparou-se, ainda, uma dieta livre de nitrogênio (dieta aprotéica) para ser utilizada na determinação da Retenção Protéica Líquida (NPR).

Os ingredientes farelo de arroz, farinha de trigo, fubá comum, fubá do milho QPM, farinha de soja e amendoim utilizados nas diferentes dietas, passaram pelo processo de torrefação. A farinha de banana foi produzida a partir de bananas verdes mergulhadas em água quente, descascadas, fatiadas com $1 \mathrm{~cm}$ de espessura, secas à temperatura ambiente, trituradas e passadas por uma peneira fina. As preparações foram efetuadas a partir da pesagem dos ingredientes, com posterior homogeneização em peneira e acondicionamento em separado (sacos plásticos), sob refrigeração até o início do experimento.

Utilizamos o parâmetro Retenção Protéica Líquida (NPR). Esse método tem a duração de 14 dias e utiliza, além das dietas a serem testadas, um controle negativo, constituído por animais sem fonte protéica na dieta, e um controle positivo, constituído por uma dieta à base de caseína (padrão). A NPR é calculada através da seguinte fórmula: [(ganho de peso (g) do grupo teste + perda de peso (g) grupo aprotéico)/proteína consumida pelo grupo teste $(\mathrm{g})]^{14}$.

Foi determinada a razão entre ganho de peso (g) e a quantidade de alimento ingerida ( $g$ ) x 100 de cada animal ao final do experimento para avaliar a eficiência alimentar.

As dietas foram submetidas à análise microbiológica para verificar a presença de 
Staphylococus aureus ${ }^{15}$.

Foi realizado custo final de cada dieta calculado a partir dos valores para cada ingrediente, informados pela Pastoral da Criança de Governador Valadares. O fubá QPM recebeu o mesmo valor do fubá comum. O valor da farinha de banana foi estimado em função da matéria prima e da mão de obra utilizada.

A análise dos dados foi realizada com o teste ANOVA. Diferenças entre as médias foram constatadas através do teste de Tukey, estabelecendo-se um nível de significância de 5\%.
Como se observa, não existe diferença no peso inicial dos animais nos diferentes grupos testados (Tabela 1). No entanto, ao final do experimento, os animais alimentados com a multimistura proposta e com a multimistura láctea com QPM, apresentaram maior peso final $(p<0,05)$. Não foi observada diferença significativa entre o peso final dos animais alimentados com dieta-padrão e dos alimentados com multimistura tradicional, com ou sem QPM $(p<0,05)$.

Os animais alimentados com as multimisturas lácteas, com ou sem QPM, e a multimistura

Tabela 1. Peso inicial e final, ingestão alimentar e ganho de peso de animais alimentados com dieta padrão ou com as diferentes multimisturas $(\mathrm{MM})^{1}$.

\begin{tabular}{lcccccc}
\hline Dietas & \multicolumn{2}{c}{ Peso Inicial $(\mathrm{g})$} & Peso Final $(\mathrm{g})$ & Ingestão alimentar $(\mathrm{g})$ & \multicolumn{2}{c}{ Ganho de Peso $(\mathrm{g})$} \\
\hline Padrão caseína & $47,12 \pm 6,49^{\mathrm{a}}$ & $81,36 \pm 13,69^{\mathrm{a}, \mathrm{b}}$ & $177,31 \pm 19,07^{\mathrm{c}}$ & 33,56 & \pm & $7,77^{\mathrm{b}}$ \\
Grupo Aprotéico & $45,08 \pm 3,50^{\mathrm{a}}$ & $34,16 \pm 2,86^{\mathrm{d}}$ & $33,28 \pm 4,38^{\mathrm{d}}$ & $-10,93$ & \pm & $1,52^{\mathrm{c}}$ \\
MM tradicional & $45,50 \pm 3,30^{\mathrm{a}}$ & $82,20 \pm 11,84^{\mathrm{a}, \mathrm{b}}$ & $204,89 \pm 34,16^{\mathrm{b}, \mathrm{c}}$ & 36,70 & \pm & $9,61^{\mathrm{b}}$ \\
MM tradicional + QPM & $45,48 \pm 3,23^{\mathrm{a}}$ & $69,58 \pm 6,09^{\mathrm{a}}$ & $163,41 \pm 20,82^{\mathrm{c}}$ & 24,10 & \pm & $6,12^{\mathrm{b}}$ \\
MM láctea & $46,08 \pm 4,53^{\mathrm{a}}$ & $108,15 \pm 16,81^{\mathrm{b}, \mathrm{c}}$ & $224,51 \pm 48,98^{\mathrm{a}, \mathrm{b}, \mathrm{c}}$ & 62,05 & $\pm 13,89^{\mathrm{a}}$ \\
MM láctea + QPM & $50,93 \pm 7,50^{\mathrm{a}}$ & $118,45 \pm 27,75^{\mathrm{c}}$ & $274,11 \pm 67,53^{\mathrm{a}, \mathrm{b}}$ & 67,52 & $\pm 20,79^{\mathrm{a}}$ \\
MM proposta & $43,60 \pm 3,44^{\mathrm{a}}$ & $119,80 \pm 17,67^{\mathrm{c}}$ & $292,78 \pm 55,52^{\mathrm{a}}$ & 76,20 & $\pm 15,62^{\mathrm{a}}$ \\
\hline
\end{tabular}

$1=$ letras iguais em uma mesma coluna significam que não houve diferença estatística. Letras diferentes significam que ocorreu diferença significativa ao nível de $5 \%$.

Tabela 2. Eficiência Alimentar e Razão Protéica Líquida (NPR) de animais alimentados com dieta padrão ou com as diferentes multimisturas (MM)'.

\begin{tabular}{lcc}
\hline Dietas & \multicolumn{1}{c}{ Eficiência } \\
& Alimentar $(\%)$ & NPR \\
\hline Padrão caseína & $18,82 \pm 3,45^{\mathrm{a}, \mathrm{b}}$ & $2,74 \pm 0,39^{\mathrm{a}}$ \\
MM tradicional & $17,72 \pm 2,68^{\mathrm{a}}$ & $1,55 \pm 0,35^{\mathrm{c}}$ \\
MM tradicional + QPM & $14,53 \pm 2,20^{\mathrm{a}}$ & $1,71 \pm 0,33^{\mathrm{b}, \mathrm{c}}$ \\
MM láctea & $28,00 \pm 4,54^{\mathrm{c}}$ & $2,46 \pm 0,42^{\mathrm{a}, \mathrm{b}}$ \\
MM láctea + QPM & $24,35 \pm 2,45^{\mathrm{b}, \mathrm{c}}$ & $2,44 \pm 0,35^{\mathrm{a}, \mathrm{b}}$ \\
MM proposta & $26,09 \pm 2,80^{\mathrm{c}}$ & $2,61 \pm 0,30^{\mathrm{a}}$ \\
\hline
\end{tabular}

\footnotetext{
1 = Letras iguais em uma mesma coluna significam que não houve diferença estatística. Letras diferentes significam que ocorreu diferença significativa ao nível de $5 \%$.
}

proposta apresentaram maior ganho de peso, quando comparados com os animais alimentados com as demais dietas $(p<0,05)$. Quanto à quantidade ingerida das dietas, ela variou entre os grupos estudados; a ingestão foi maior para a multimistura proposta, quando comparada com a dieta padrão ou com a multimistura tradicional, com e sem QPM $(p<0,05)$.

Foi menor a eficiência alimentar para as multimisturas tradicionais com e sem QPM, quando comparadas com a multimistura proposta ou com as misturas lácteas com e sem QPM (Tabela 2). 
Como se observa, não ocorreu diferença nos valores de NPR entre a dieta padrão e as multimisturas láctea, láctea com QPM e a multimistura proposta, as quais se apresentam iguais entre si $(p<0,05)$ (Tabela 2$)$. Porém, as multimisturas tradicional e tradicional com QPM apresentaram valores de NPR significativamente inferiores quando comparadas com a dieta padrão $(p<0,05)$. A multimistura láctea e a láctea com QPM não apresentaram diferença significativa em relação à multimistura tradicional com QPM. No entanto, houve diferença estatística em relação à multimistura tradicional. A multimistura proposta apresentou valores de NPR significativamente maiores do que a multimistura tradicional e tradicional com QPM $(p<0,05)$.

Todas as multimisturas apresentaram índices de bolores, leveduras e de Staphylococus aureus dentro do padrão microbiológico aceitável. Por sua vez, a análise de coliformes fecais indicou que apenas a multimistura proposta apresentou valores de contaminação dentro do padrão aceitável. Tais resultados se restringem apenas às amostras analisadas.

$O$ custo da multimistura tradicional foi de $\mathrm{R} \$ 2,60 / \mathrm{kg}$; A multimistura tradicional com QPM ficou em $\mathrm{R} \$ 2,65 / \mathrm{kg}$; Por sua vez, a multimistura láctea, a multimistura látea com QPM e a multimistura proposta ficaram em $\mathrm{R} \$ 2,45 ; 2,42$ e $1,60 / \mathrm{kg}$, respectivamente.

\section{I S C U S S Ã O}

Neste trabalho é analisada uma multimistura baseada no milho QPM BR 473, uma variedade de milho com alto valor protéico. Este milho apresenta um perfil aminoacídico rico nos aminoácidos essenciais lisina e triptofano, cujas concentrações são maiores do que no milho comum ${ }^{12}$.

O fubá do milho QPM pode substituir com vantagens os farelos de trigo e de arroz e os pós da casca de ovo e da folha de mandioca, componentes da multimistura tradicional, os quais podem conter fatores antinutricionais - ácido fítico e ácido cianídrico, por exemplo. Outra vantagem é ser o milho considerado alimento, recebendo portanto, tratamento mais cuidadoso do ponto de vista higiênico-sanitário o que não ocorre com folhas e cascas ${ }^{6,7}$.

Os resultados aqui apresentados mostram que, de um modo geral, a multimistura tradicional, com e sem QPM, apresentou valores significativamente menores para peso final, ganho de peso, quantidade de dieta ingerida e eficiência alimentar, quando comparados aos valores obtidos com a multimistura proposta e as multimisturas lácteas, com e sem QPM. Cabe ressaltar que, comparando-se os mesmos parâmetros, as multimisturas lácteas com e sem QPM apresentaram resultados semelhantes. Esses dados corroboram aqueles obtidos para a NPR (Tabela 1). Os ratos alimentados com uma dieta à base de fubá QPM (multimistura proposta) apresentaram valores de NPR significativamente maiores quando comparados aos valores obtidos de ratos alimentados com a dieta à base de multimistura tradicional; por outro lado, a adição do fubá QPM, em substituição ao farelo não alterou a eficiência protéica da multimistura tradicional (Tabela 1). Isto deve-se, provavelmente, à presença de fatores antinutricionais nos pós das casca de ovo e da folha de mandioca e, também, a uma composição nutricional não balanceada da multimistura tradicional (Tabela 3). Resultado semelhante foi obtido por Heinemann et al. ${ }^{16}$ em dieta suplementada com proteína da folha de mandioca e farinha de trigo. Também nesse caso, a ausência de modificação da eficiência protéica se deve provavelmente a fatores antinutricionais.

Não observamos diferenças entre os valores de NPR para a multimistura proposta e a multimistura láctea, o que se deve, provavelmente, à composição mais complexa e nutricionalmente equilibrada (densidade energética e proteínas de alto valor biológico). Ressalta-se que a multimistura láctea é utilizada pela Pastoral da Criança de Governador Valadares, em ações locais, visando à recuperação de crianças desnutridas; daí o interesse em conhecer sua qualidade protéica. 
Tabela 3. Composição das diferentes multimisturas testadas (g/100g).

\begin{tabular}{|c|c|c|c|c|c|}
\hline Componentes (g) & MM Tradicional & $\begin{array}{c}\text { MM Tradicional + Fubá } \\
\text { QPM }\end{array}$ & MM Láctea & $\begin{array}{c}\text { MM Láctea + Fubá } \\
\text { QPM }\end{array}$ & MM Proposta \\
\hline Farelo de arroz & 32,00 & - & 13,50 & - & - \\
\hline Fubá comum & 32,00 & & 13,50 & - & - \\
\hline Farinha de trigo & 32,00 & 32,00 & 13,50 & 13,50 & - \\
\hline Pó da folha de mandioca & 2,00 & 2,00 & 0,70 & 0,70 & - \\
\hline Pó da casca de ovo & 2,00 & 2,00 & 0,70 & 0,70 & - \\
\hline Fubá QPM & - & 64,00 & - & 27,00 & 45,00 \\
\hline Farinha de mandioca & - & - & 13,50 & 13,50 & - \\
\hline Farinha de soja & - & - & 6,80 & 6,80 & 15,00 \\
\hline Aveia & - & - & 6,80 & 6,80 & 10,00 \\
\hline Amendoim & - & - & 6,80 & 6,80 & - \\
\hline Leite em pó & - & - & 10,80 & 10,80 & - \\
\hline Açúcar mascavo & - & - & 13,50 & 13,50 & 10,00 \\
\hline Farinha de banana & - & - & - & - & 20,00 \\
\hline Carboidratos (g/100g) & 62,15 & 73,10 & 61,15 & 65,77 & 70,21 \\
\hline Proteínas (g/100g) & 11,75 & 10,24 & 14,08 & 13,45 & 13,01 \\
\hline Lipídios (g/100g) & 6,53 & 3,27 & 9,88 & 8,50 & 3,76 \\
\hline Energia (KJ) & 1468,43 & 1515,04 & 1612,56 & 1632,46 & 1510,44 \\
\hline
\end{tabular}

Na comparação entre multimisturas, outros fatores além da avaliação protéica devem ser considerados, tal como a condição microbiológica (resultante de condições de manipulação, processamento e armazenamento). A análise da amostra da multimistura proposta apresentou padrões microbiológicos aceitáveis pela legislação, o mesmo não ocorrendo com as demais. Outro fator relevante avaliado foi o custo, o qual, para a multimistura proposta foi $32 \%$ menor do que para as demais. Além desses fatores, a aceitabilidade é imprescindível, uma vez que valor nutricional elevado e baixo custo não são condições suficientes para garantir o sucesso desse tipo de produto ${ }^{17}$. Quanto à multimistura proposta, mostrou boa aceitabilidade nas preparações culinárias em que foi utilizada.

Esta pesquisa introduziu pela primeira vez o milho QPM BR 473 como ingrediente de um complemento alimentar. Este complemento associa eficiência protéica (equilíbrio protéico-energético), qualidade sanitária, baixo custo e boa aceitabilidade, aliados à ausência dos componentes da multimistura tradicional criticados pela comunidade científica brasileira. Novos estudos utilizando o BR 473 estão sendo realizados para complementar as informações aqui apresentadas. Além das pesquisas, que dão o respaldo científico no uso do milho QPM como um complemento nutricional, outras ações envolvendo a produção e o consumo desse milho estão sendo desencadeadas no combate à desnutrição, tais como a formação de grupos de geração de renda e o fortalecimento da agricultura familiar.

\section{O N C L U S Ã O}

Concluiu-se como complemento alimentar, a multimistura proposta apresentou-se superior à multimistura tradicional, sem os inconvenientes característicos da formulação habitual.

\section{A GRADECIMENTOS}

Nossos sinceros agradecimentos à Profa. Dra. Lúcia A.O. Fraga, ao Prof. João Carlos Martinelli e à aluna Lílian S.V. Malaquias, todos da UNIVALE; à Aimara C. Pinheiro, do Serviço de Vigilância Sanitária e à Vera Lúcia S. Araújo, da Secretaria Municipal de Saúde de GV. 


\section{REFERÊ NCIAS}

1. Torin HR. Utilização do farelo de arroz industrial: composição e valor nutrificante em dietas recuperativas [dissertacão]. Campinas: Universidade Estadual de Campinas; 1991.

2. Nogara $C D$, Marsiglia $D$, Sigulem DM, Palma $D$, Lopez FA, Nóbrega FJ, et al. Recuperação nutricional de grupos de populacionais de baixa renda: análise crítica. Bol Soc Bras Ciênc Tecnol Alim 1995; 29(2):114-26.

3. Amaya-Farfan J. Alimentação alternativa: análise crítica de uma proposta de intervenção nutricional. Cad Saúde Pública 1998; 14:205-11.

4. Santos LAS, Lima AMP, Passos IV, Santos LMP, Santos SMC, Soares MD. Uso e percepções da alimentação alternativa no estado da Bahia. Rev Nutr 2001; 14 Supl:35-40.

5. Amâncio OMS, Lajolo FM, Santoro M, Nóbrega FJ، Queiroz SS, Amaya-Farfan J. Recuperação nutricional de grupos populacionais de baixa renda: análise crítica. Cad Nutr 1995; 9(3):1-4.

6. Torin HR, Domene SMA, Amaya-Farfan J. Informe técnico: programas emergenciais de combate a fome e o uso de sub-produtos de alimentos. Rev Ciências Médicas - PUCCAMP 1996; 5(2):87-98.

7. Bittencourt SA. Uma alternativa para a política nutricional brasileira? Cad Saúde Pública 1998; 14(3):629-36.

8. Bion FM, Pessoa DCNDP, Lapa MAG, Câmara FA, Campos FACS, Antunes NLM, et al. Uso de uma multimistura como suplementação alimentar: estudo em ratos. Arch Latinoam Nutr 1997; 47(3):242-7.

9. Boaventura GT, Chiappin CCJ, Assis-Fernandes NR, Oliveira EM. Avaliação da qualidade protéica de uma dieta estabelecida em Quissamã, Rio de
Janeiro, adicionada ou não de multimistura e de pó de folha de mandioca. Rev Nutr 2000; 13(3):201-9.

10. Assis AMO, Prado MS, Franco VB, Conceição LM, Martinez $Y$, Martinez $L$, et al. Suplementação da dieta com farelo de trigo e o estado nutricional de crianças de 1 a 7 anos de idade. Rev Nutr PUCCAMP 1996; 9(1):92-107.

11. Paes MCD. Perspectivas nutricionais do milho de alta qualidade protéica: óleos e grãos 1995; 24:49-52.

12. Nutritional perspectives of quality protein maize. In: Proceedings of the 94th International Symposium on quality protein maize. West Lafayette: Purdue University; 1997.

13. Association of official agricultural chemists. Offical Methods of Analysis. 10th ed. Washington, DC; 1965.

14. Miller GA, Lachance PA. Techniques in rat bioassays. In: Bodwell CE, editor Evaluation of proteins for humans. New York: Publishing Company; 1977. p.149-61.

15. International Comission on Microbiological Specification for Foods (ICMSF). 2nd ed. Toronto: University of Toronto Press; 2003.

16. Heinemann RB, Costa NMB, Cruz R, Pirozi MR. Valor nutricional de farinha de trigo combinada com concentrado protéico de folha de mandioca. Rev Nutr 1998; 11(1):51-7.

17. Câmara FS, Madruga MS. Cyanic acid, phytic acid, total tannin and aflatoxin contents of a Brazilian (Natal) multimistura preparation. Rev Nutr 2001; 14(1):33-6.

Recebido para publicação em 16 de janeiro e aceito em 11 de outubro de 2003. 